\title{
Supercharging with Trivalent Metal Ions in Native Mass Spectrometry
}

\author{
Tawnya G. Flick, Evan R. Williams \\ Department of Chemistry, University of California-Berkeley, Berkeley, CA 94720-1460, USA
}

\begin{abstract}
Addition of $1.0 \mathrm{mM} \mathrm{LaCl}_{3}$ to aqueous ammonium acetate solutions containing proteins in their folded native forms can result in a significant increase in the molecular ion charging obtained with electrospray ionization as a result of cation adduction. In combination with $m$-nitrobenzyl alcohol, molecular ion charge states that are greater than the number of basic sites in the protein can be produced from these native solutions, even for lysozyme, which is conformationally constrained by four intramolecular disulfide bonds. Circular dichroism spectroscopy indicates that the conformation of ubiquitin is not measurably affected with up to $1.0 \mathrm{M} \mathrm{LaCl}_{3}$, but ion mobility data indicate that the high charge states that are formed when $1.0 \mathrm{mM} \mathrm{LaCl} \mathrm{m}_{3}$ is present are more unfolded than the low charge states formed without this reagent. These and other results indicate that the increased charging is a result of $\mathrm{La}^{3+}$ preferentially adducting onto compact or more native-like conformers during ESI and the gas-phase ions subsequently unfolding as a result of increased Coulomb repulsion. Electron capture dissociation of these high charge-state ions formed from these native solutions results in comparable sequence coverage to that obtained for ions formed from denaturing solutions without supercharging reagents, making this method a potentially powerful tool for obtaining structural information in native mass spectrometry.
\end{abstract}

Key words: Metalions, Supercharging, Proteins, Native mass spectrometry, Electrospray ionization

\section{Introduction}

$\mathrm{E}$ lectrospray (ESI) ionization is widely used to generate intact multiply charged ions of proteins and protein complexes from aqueous solutions, a technique often referred to as native mass spectrometry (MS) [1-4]. The multiple charging of large molecules that typically occurs with ESI is advantageous for lowering $\mathrm{m} / \mathrm{z}$ values into a range where high performance mass measurements can be made $[5,6]$. Increasing analyte charge also increases the sensitivity of mass spectrometers where the signal of

Electronic supplementary material The online version of this article (doi:10.1007/s13361-012-0463-2) contains supplementary material, which is available to authorized users.

Correspondence to: Evan R. Williams; e-mail: williams@cchem.berkeley.edu

Published online: 05 September 2012 an ion is proportional to its charge, such as Orbitrap and Fourier-transform ion cyclotron resonance (FT-ICR) instruments [7,8].

Several factors affect the extent of analyte charging by ESI, including analyte conformation [9-11], solvent and analyte basicity [12-14], instrumental factors [15, 16], and solvent surface tension [17-19]. Broad charge state distributions of molecular ions centered about high charge are typically observed from solutions in which proteins are unfolded, whereas narrow distributions at low charge are obtained for proteins and protein complexes formed from solutions in which these molecules have native structures [9-11]. The solution-phase denaturation of proteins as a result of heating or acidifying the bulk ESI solution can be monitored by ESI-MS from shifts in the charge state distribution towards higher charge [10, 11]. Complexation of multivalent metal ions can also increase the charge states 
of molecular ions formed by ESI [20-23], and has been used effectively to obtain electron capture dissociation (ECD) spectra of small peptides for which multiply protonated ions are not typically formed [21-23].

An effective method to increase the charging observed for many biomolecules is the use of supercharging reagents, such as $m$-nitrobenzyl alcohol ( $m$-NBA) [17-19, 24-37]. Originally demonstrated for protein ions formed from denaturing solutions [17-19], this supercharging method is also effective at increasing the charge states of protein and protein complex ions formed from native solutions [24-31]. Supercharging reagents have high boiling points and the concentrations of these reagents increase as ESI droplet evaporation occurs [31, 32]. Enrichment of the supercharging reagent affects many physical properties of the ESI droplet, including the surface tension, temperature, propensities to proton transfer, etc. Results from circular dichroism spectroscopy [29, 31] and hydrogen-deuterium exchange MS [30, 31] indicate the supercharging reagents do not affect protein conformation at the low concentrations typically used in the initial solutions, but can cause chemical and/or thermal denaturation of the protein in the ESI droplet as the concentration of these reagents is increased. Proteins that have lost some or all of their native structures can carry away more charge and the charge enhancement from the denaturing effect is greater than the effect of the lower surface tension [28].

High charge state ions typically dissociate more readily to produce structurally useful information, which can lead to higher sequence coverage in tandem mass spectrometry experiments with peptides and proteins [38, 39]. This is especially the case with electron capture or transfer dissociation where extensive sequence coverage can be obtained from the high charge state molecular ions of proteins that are typically formed from denaturing solutions $[40,41]$. However, information about the native conformation, protein-substrate interactions, or stoichiometry of macromolecular assemblies can be lost under denaturing conditions. Supercharging improves the ability to combine "top-down" tandem mass spectrometry with native mass spectrometry, which can be used to read out encoded information about conformations and conformational changes that occur in solution, such as solution-phase H/D exchange rates [30] and other labeling strategies, or identifying proteinligand binding sites directly from fragmentation of an intact complex [36].

The charge states of proteins generated by ESI from unbuffered aqueous solutions can also be increased by introducing acid vapor into the drying gas of an ESI interface [42]. Addition of $\mathrm{HCl}$ acid vapor into the drying gas resulted in an increase in the maximum charge state of cytochrome $c$ by 10 and a shift in the average state from 8.9 to 15.4 compared to that obtained when no acid vapor was introduced [42]. The acid vapor lowers the $\mathrm{pH}$ of the ESI droplet and acid denaturation of the protein occurs, resulting in higher ion charge states in the mass spectrum [42]. An electrothermal supercharging method to generate high charge state protein ions with ESI from buffered aqueous solutions in which the proteins have native structures was recently introduced [43]. ESI mass spectra resembling those obtained from denaturing solutions, where the maximum extent of charging can exceed the number of basic sites in the molecule, can be obtained with this method [43]. The effectiveness of this method to increase charging depends on a number of different factors, but ESI mass spectra resembling those measured from standard native or denatured solutions can be reversibly obtained simply by toggling the electrospray voltage between low and high values [43]. This method has the advantage over acidification of the ESI droplets in that it can be used with aqueous solutions that have high buffer capacity [43].

Here, addition of millimolar concentrations of $\mathrm{La}^{3+}$ to aqueous protein-containing solutions is shown to increase the extent of protein charging by ESI as a result of $\mathrm{La}^{3+}$ adduction onto native protein conformers. The enhanced protein charging via $\mathrm{La}^{3+}$ adduction is slightly lower than that obtained from aqueous ammonium acetate solutions that contain the supercharging reagent $m$-NBA, but both $m$-NBA and $\mathrm{LaCl}_{3}$ can be used in combination to readily form charge states in excess of the number of basic sites in the protein. ECD of high charge states generated by trivalent metal ion supercharging from aqueous solutions results in improved fragmentation efficiency and sequence coverage compared with that obtained from the highest charge state formed from aqueous solutions without $\mathrm{La}^{3+}$.

\section{Experimental}

\section{Mass Spectrometry}

Experiments were performed using a $9.4 \mathrm{~T}$ FT-ICR mass spectrometer equipped with an external ESI source [44]. Bovine ubiquitin, bovine cytochrome $c$, chicken egg white lysozyme, $\mathrm{LaCl}_{3}, m$-nitrobenzyl alcohol ( $m$-NBA), methanol, acetic acid, and ammonium acetate were all purchased from Sigma Aldrich (St. Louis, MO, USA). Stock solutions containing $10 \mu \mathrm{M}$ protein were prepared in either water with $5 \mathrm{mM}$ ammonium acetate or with 48.5/48.5/3.0 methanol/ water/acetic acid ( $\mathrm{vol} / \mathrm{vol} / \mathrm{vol})$. A small volume of sample solution $(\sim 2-10 \mu \mathrm{L})$ is loaded into a borosilicate capillary $(1.0 \mathrm{~mm}$ o.d./0.78 mm i.d.; Sutter Instruments, Novato, CA, USA) that is pulled to a tip with an inner diameter of $\sim 2 \mu \mathrm{m}$ (model P-87 capillary puller; Sutter Instruments). A grounded platinum wire is inserted into the solution and the capillary is positioned $\sim 2 \mathrm{~mm}$ away from the source inlet capillary to which a potential of -800 to $-1200 \mathrm{~V}$ is applied. Ions are accumulated in an external hexapole ion trap for $2.0 \mathrm{~s}$ and are subsequently injected into the ion cell, and this process is repeated two additional times in order to load the ion cell. For ECD experiments, the precursor ion of interest is isolated using stored waveform inverse Fourier transforms (SWIFTs) [45] with a $2 \mathrm{kHz}$ or wider window around the precursor. Electrons from a heated dispenser cathode (Heatwave Labs, Watsonville, CA, USA) that is mounted 
axially from the cell center are introduced into the ion cell $100 \mathrm{~ms}$ after ion isolation by changing the cathode housing potential from $+10 \mathrm{~V}$ to either -0.40 or $-0.65 \mathrm{~V}$ for $100 \mathrm{~ms}$. Ions are detected $1.0 \mathrm{~s}$ after electron irradiation. EC efficiency $\left(\mathrm{Eff}_{\mathrm{EC}}\right)$ is calculated using Equation 1

$$
E f f_{E C}=\frac{\Sigma I_{\text {fragment }}+\Sigma I_{\text {reduced }}}{I_{\text {precursor }}+\Sigma I_{\text {reduced }}+\Sigma I_{\text {fragment }}}
$$

where $I_{\text {precursor }}, I_{\text {fragment }}$, and $I_{\text {reduced }}$ are ion abundances of the precursor remaining after the ECD event, the fragments, and the reduced precursors, respectively. Fragmentation efficiency $\left(E f f_{f r a g}\right)$ is calculated using Equation 2

$$
E f f_{\text {frag }}=\frac{\Sigma I_{\text {fragment }}}{I_{\text {precursor }}+\Sigma I_{\text {reduced }}+\Sigma I_{\text {fragment }}}
$$

The measured ion abundances were normalized for charge, but effects of any $m / z$-dependent detection efficiency or isotopes not included in these calculations were not taken into account. Uncertainties for electron capture and fragmentation efficiencies are reported as \pm one standard deviation of three replicate measurements. Each measurement was repeated with a different SWIFT for isolation with a window between two to four $\mathrm{kHz}$ around the precursor. Off-resonance excitations can transfer kinetic energy into ions, but this effect decreases as the frequency of the excitation becomes more off-resonance [46]. Changing the SWIFT window between these values changes the extent of off-resonance excitation that occurs [45], but there was no significant effect on either the electron capture or fragmentation efficiencies. These results indicate that the SWIFT isolations do not measurably affect the overlap of the precursor ions and the electrons. The reported signal-to-noise ratios $(\mathrm{S} / \mathrm{N})$ are determined directly from the mass spectral data and are not normalized for ion charge.

\section{Circular Dichroism}

Circular dichroism (CD) spectra were acquired on a Jasco model 810 spectropolarimeter (JASCO, Inc., Easton, MD, USA) from solutions containing $20 \mu \mathrm{M}$ ubiquitin in denaturing solution conditions (48.5/48.5/3 methanol/water/ acetic acid) or water with $5.0 \mathrm{mM}$ ammonium acetate either with no additional additive or $1.0 \mathrm{mM}$ to $5.0 \mathrm{M} \mathrm{LaCl}_{3}$. Samples were transferred to a $1.0 \mathrm{~cm}$ quartz cuvette with constant mixing using a Teflon stir bar while performing a wavelength scan analysis from 210 to $250 \mathrm{~nm}$.

\section{Ion Mobility}

Ion mobility experiments were performed using a Synapt G2 High Definition mass spectrometer (Waters, Milford, MA, USA) equipped with a Z-spray ion source. Ions are formed by ESI as described above using a platinum wire potential of 1.0 to $1.5 \mathrm{kV}$. The sample and extraction cone potentials were 40 and $3 \mathrm{~V}$, respectively. The traveling wave ion mobility cell was operated with a constant wave velocity of $700 \mathrm{~m} / \mathrm{s}$, wave height of $40 \mathrm{~V}$, helium flow rate of $180 \mathrm{~mL} /$ min, and IMS $\left(\mathrm{N}_{2}\right)$ flow rate of $90 \mathrm{~mL} / \mathrm{min}$. The time of flight mass analyzer was operated in sensitivity mode ("V"). Drift times were converted to a collision cross section (ccs) scale using the procedure outlined by Robinson and coworkers $[47,48]$ with ubiquitin $(9+$ through $13+)$, cytochrome $c(13+$ through $18+)$, and myoglobin $(16+$ through $22+)$ formed from denaturing solutions as calibrant ions. An average ccs was obtained for a given charge state of ubiquitin by weighting the ccs for each conformation by peak area.

\section{Results and Discussion}

\section{Trivalent Metal Ion Supercharging in Aqueous Solutions}

The 5+ charge state of ubiquitin is the most abundant ion produced by ESI (aqueous $5.0 \mathrm{mM}$ ammonium acetate), and the average and maximum charge states are 5.2 and 7 , respectively (Figure 1a). With $1.0 \mathrm{mM} \mathrm{LaCl}_{3}$ added to this solution, the average (7.6) and maximum (11) charge states are significantly higher (Figure $1 \mathrm{~b}$ ). More $\mathrm{La}^{3+}$ ions adduct to the higher charge state ions. The average number of $\mathrm{La}^{3+}$ adducts increases from 1.7 to 3 for the $6+$ and $11+$ charge states, respectively. About $12 \%$ of the $6+$ molecular ions are fully protonated whereas all ions of the $11+$ charge state have $\mathrm{La}^{3+}$ bound. Similar results were also obtained from ESI of an aqueous solution containing $1.0 \mathrm{mM} \mathrm{EuCl}_{3}$ (data not shown), suggesting that the binding of these metal ions to the protein is not specific. In contrast, ESI of an aqueous solution of ubiquitin containing $1.0 \mathrm{mM} \mathrm{NaCl}$ results in no significant change to the average charge state (5.0), and $\mathrm{Na}^{+}$ adduction occurs more substantially to the lower charge state ions (data not shown), a result consistent with previous reports $[49,50]$. The greater adduction of $\mathrm{La}^{3+}$ to higher charge states of ubiquitin suggests that the higher charge states that are formed with $\mathrm{LaCl}_{3}$ are due to the added charge of these trivalent metal ions when they adduct to ubiquitin which is folded in solution.

To compare the extent of charge enhancement obtained from native solutions with $\mathrm{LaCl}_{3}$ to conventional supercharging reagents [24-31], an ESI mass spectrum of an aqueous solution of ubiquitin with $1.0 \% \mathrm{~m}$-NBA was obtained under identical conditions (Figure 1c). The charge state distribution is slightly broader than that obtained with $\mathrm{LaCl}_{3}$ and it is centered about 9+ with an average charge state of 8.5. The maximum charge state (11) that is formed is the same for both $m$-NBA or $\mathrm{LaCl}_{3}$, but with $m$-NBA, the average charge state is one higher and the abundance of the maximum charge state is greater.

To determine whether the combination of trivalent metal ion adduction and $m$-NBA results in more charging than either reagent individually, an ESI mass spectrum of ubiquitin from 


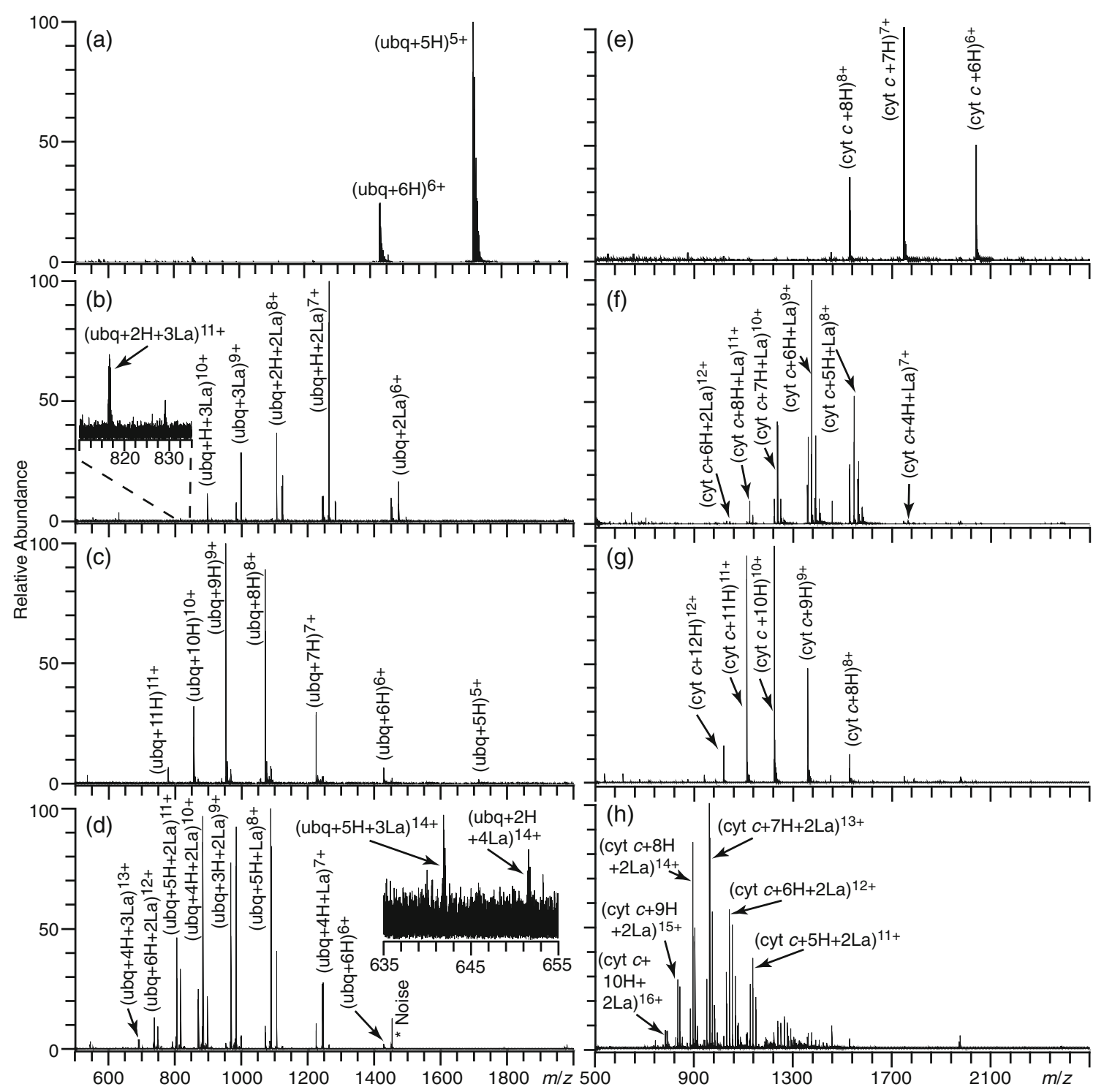

Figure 1. ESI mass spectra of aqueous solutions of $10 \mu \mathrm{M}$ ubiquitin or cytochrome $c$ in $5 \mathrm{mM}$ ammonium acetate containing (a) and (e) no additives, (b) and (f) $1.0 \mathrm{mM} \mathrm{LaCl}_{3}$, (c) and (g) $1.0 \% \mathrm{~m}$-NBA, or (d) and (h) $1.0 \mathrm{mM} \mathrm{LaCl}_{3}$, and $1.0 \% \mathrm{~m}$-NBA, respectively

an aqueous solution containing both $1.0 \% \mathrm{~m}$-NBA and $1.0 \mathrm{mM} \mathrm{LaCl}_{3}$ was obtained (Figure 1d). The average (9.8) and maximum (14) charge states are greater than those obtained with either $\mathrm{LaCl}_{3}$ or $m$-NBA alone. Higher charge states have more $\mathrm{La}^{3+}$ adduction, as occurred without $m$-NBA. The $12+$ to $14+$ charge states all have $\mathrm{La}^{3+}$ bound, whereas $\mathrm{La}^{3+}$ is adducted to only $9.5 \%$ of the $7+$ charge state ions. Ubiquitin has 13 basic sites consisting of 12 basic amino acids (H, R, and $\mathrm{K}$ ) and the $\mathrm{N}$-terminus. Thus, formation of the $14+$ charge state corresponds to charging greater than the number of basic sites in the protein despite formation of these ions from an aqueous solution in which ubiquitin has a folded structure.

Similar results were obtained for bovine cytochrome $c$, a larger protein with a higher isoelectric point than ubiquitin. The average and maximum charge states of cytochrome $c$ in an ESI mass spectrum from an aqueous solution with $5.0 \mathrm{mM}$ ammonium acetate are 6.9 and 8 , respectively (Figure 1e). With $1.0 \mathrm{mM} \mathrm{LaCl}_{3}$, the average and maximum charge states in the ESI mass spectrum increase to 8.9 and 13 , respectively (Figure 1f). The average (10.3) and maximum (14) charge states with $1.0 \% \mathrm{~m}$-NBA are slightly higher than those obtained with $1.0 \mathrm{mM} \mathrm{LaCl}_{3}$ (Figure 1g). With both $m$-NBA and $\mathrm{LaCl}_{3}$, the average (12.5) and maximum (17) charge states are 5.6 and 9 more charges, respectively, than those formed from ammonium acetate alone (Figure $1 \mathrm{~h}$ ).

To determine the extent to which intramolecular disulfide bridges, which reduce the conformational flexibility of a protein, can affect the charge enhancement by $\mathrm{LaCl}_{3}$, an ESI mass spectrum of an aqueous solution (5.0 $\mathrm{mM}$ ammonium acetate) containing $10 \mu \mathrm{M}$ lysozyme and $1.0 \mathrm{mM} \mathrm{LaCl}{ }_{3}$ was obtained (Figure S1). With $1.0 \mathrm{mM} \mathrm{LaCl}_{3}$, the average and maximum charge states increase from 8.0 to 9.7 and 10 to 12 , respectively, 
compared with those obtained from the solution containing ammonium acetate alone. An aqueous solution containing both $1.0 \mathrm{mM} \mathrm{LaCl} 3$ and $1.0 \% \mathrm{~m}$-NBA results in average and maximum charge states of 11.8 and 20, respectively. Lysozyme has 19 basic sites, and the formation of the 20+ charge state indicates that charge states greater than the number of basic sites can be generated from a native solution even for a protein that is conformationally constrained by disulfide bonds.

\section{Effect of Supercharging Additives on $S / N$}

The effects of $\mathrm{LaCl}_{3}$ and $m$-NBA, individually and combined, on the signal-to-noise ratios $(\mathrm{S} / \mathrm{N})$ of the most abundant ion and total ion abundance for ubiquitin, cytochrome $c$, and lysozyme are shown in Table 1. There is little to no adverse affect on ESI signal for any of these proteins with $1.0 \% \mathrm{~m}$-NBA, consistent with previous results [18]. Similarly, $1.0 \mathrm{mM} \mathrm{LaCl}_{3}$ has little effect on the total ion abundance, but does lower the $\mathrm{S} / \mathrm{N}$ for the most abundant ion. The $\mathrm{S} / \mathrm{N}$ of the most abundant ion is $39 \%$, $13 \%$, and $37 \%$ lower for ubiquitin, cytochrome $c$, and lysozyme, respectively, with $1.0 \mathrm{mM} \mathrm{LaCl}{ }_{3}$ compared with ammonium acetate alone, as a result of ion abundance being distributed into multiple peaks with varying numbers of $\mathrm{La}^{3+}$ adducts. With both $m$-NBA and $\mathrm{LaCl}_{3}$, the total ion abundance for all three proteins is reduced compared with ammonium acetate alone. Similar to results with just $\mathrm{LaCl}_{3}$, the $\mathrm{S} / \mathrm{N}$ of the most abundant ion is significantly reduced $(\sim 2-9 \times)$ because ion abundance is distributed over varying numbers of $\mathrm{La}^{3+}$ adducts.

\section{Effect of $\mathrm{La}^{3+}$ on Protein Conformation}

High charge state protein ions can be formed by ESI from solutions in which the protein is unfolded, or when protein unfolding occurs in the ESI droplet [26-31, 42]. The effect of $\mathrm{LaCl}_{3}$ on protein conformation in solution was investigated using circular dichroism (CD). Far-UV CD spectra $(210-250 \mathrm{~nm})$, which probes the $\alpha$-helical and $\beta$-sheet content of a protein, were acquired for ubiquitin in a denaturing solution, $5.0 \mathrm{mM}$ ammonium acetate solution, and $5.0 \mathrm{mM}$ ammonium acetate solution containing between
$1.0 \mathrm{mM}$ to $5.0 \mathrm{M} \mathrm{LaCl}_{3}$ (Figure 2a). The CD signal in this spectral region is the same with and without $\mathrm{LaCl}_{3}$ for concentrations up to $1.0 \mathrm{M}$, indicating that there is no measurable change in the secondary structure of ubiquitin. With $5.0 \mathrm{M} \mathrm{LaCl}_{3}$, the $\mathrm{CD}$ spectrum is distinctly different, indicating that the secondary structure changes at this high salt concentration. The CD spectrum of denatured ubiquitin has a notable decrease in ellipticity at $220 \mathrm{~nm}$ compared with that obtained for the folded form from native solutions, which is consistent with an increase in $\alpha$-helical content characteristic of the denatured A-state form of ubiquitin [51].

Ion mobility experiments were performed to investigate how $\mathrm{La}^{3+}$ adduction affects the conformations of the resulting gaseous ubiquitin ions. There are multiple conformers for many charge states of ubiquitin (Figure S2), consistent with previous studies [52, 53]. To simplify comparisons, the average ccs for each charge state was determined by weighting each feature in the drift profile by peak area. The average ccs as a function of the charge state of ubiquitin for fully protonated ions generated from native and denaturing solutions, and for ions with two or three $\mathrm{La}^{3+}$ adducts formed from aqueous solutions containing $\mathrm{LaCl}_{3}$ is shown in Figure $2 b$. For the fully protonated ions generated from a denaturing solution, the average ccs increases with increasing charge, as previously reported [52, 53]. For aqueous solutions containing $1.0 \mathrm{mM} \mathrm{LaCl}$, the average ccs of ubiquitin ions with two or three $\mathrm{La}^{3+}$ adducts also increases with increasing charge state, and the $8+$ to $14+$ $\mathrm{La}^{3+}$ adducted ubiquitin ions have more elongated conformations compared with the fully protonated $5+$ and $6+$ charge states formed from ammonium acetate alone. However, the average ccs values of the $\mathrm{La}^{3+}$ adducted ions are consistently smaller than the corresponding protonated form with the same charge state generated from either a native or denaturing solution. The more compact structures may be a result of strong salt-bridge or charge-solvation interactions between the metal ion and deprotonated residues or polarizable atoms in the protein [54] or it may be due to lower charge-charge repulsion as a result of fewer charge carriers that are more highly charged but are spaced further apart compared with the fully protonated ion. The CD data

Table 1. The Most Abundant Ion $\mathrm{S} / \mathrm{N}$ and Total Ion Abundance $\mathrm{S} / \mathrm{N}$ of Ubiquitin, Cytochrome $c$, or Lysozyme from the ESI Mass Spectra of Aqueous Solutions (5 mM Ammonium Acetate) with and without Supercharging Additives

\begin{tabular}{|c|c|c|c|c|}
\hline Protein & Additive & Most abundant ion & Most abundant ion $\mathrm{S} / \mathrm{N}$ & Total ion abundance $\mathrm{S} / \mathrm{N}$ \\
\hline \multirow[t]{4}{*}{ Ubiquitin } & None & ${\text { (ubiquitin }+5 \mathrm{H})^{5+}}^{5+}$ & 9068 & 27,256 \\
\hline & $1.0 \% \mathrm{~m}-\mathrm{NBA}$ & $(\text { ubiquitin }+9 \mathrm{H})^{9+}$ & 8380 & 25,524 \\
\hline & $1.0 \mathrm{mM} \mathrm{LaCI}_{3}$ & 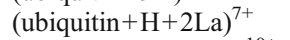 & 5487 & 23,713 \\
\hline & $1.0 \% \mathrm{~m}-\mathrm{NBA} \& 1.0 \mathrm{mM} \mathrm{LaCI}_{3}$ & ${\text { (ubiquitin }+4 \mathrm{H}+2 \mathrm{La})^{10+}}^{10}$ & 955 & 9734 \\
\hline \multirow{4}{*}{ Cytochrome $c$ (cyt $c$ ) } & None & $(\operatorname{cyt} c+7 \mathrm{H})^{7+}$ & 7943 & 17,475 \\
\hline & $1.0 \% \mathrm{~m}-\mathrm{NBA}$ & $(\text { cyt } c+10 \mathrm{H})^{10+}$ & 8332 & 23,330 \\
\hline & $1.0 \mathrm{mM} \mathrm{LaCI}_{3}$ & $(\text { cyt } c+6 \mathrm{H}+\mathrm{La})^{9+}$ & 6896 & 17,930 \\
\hline & $1.0 \% \mathrm{~m}-\mathrm{NBA} \& 1.0 \mathrm{mM} \mathrm{LaCI}_{3}$ & $(\text { cyt } c+7 \mathrm{H}+2 \mathrm{La})^{13+}$ & 2786 & 7244 \\
\hline \multirow{4}{*}{ Lysozyme (lys) } & None & $(\text { lys }+8 \mathrm{H})^{8+}$ & 12,345 & 17,283 \\
\hline & $1.0 \% \mathrm{~m}-\mathrm{NBA}$ & $(\text { lys }+11 \mathrm{H})^{11+}$ & 10,452 & 24,040 \\
\hline & $1.0 \mathrm{mM} \mathrm{LaCI}_{3}$ & $(\text { lys }+7 \mathrm{H}+\mathrm{La})^{10+}$ & 7782 & 17,439 \\
\hline & $1.0 \% \mathrm{~m}-\mathrm{NBA} \& 1.0 \mathrm{mM} \mathrm{LaCI}_{3}$ & $(\text { lys }+11 \mathrm{H})^{11+}$ & 5481 & 13,703 \\
\hline
\end{tabular}



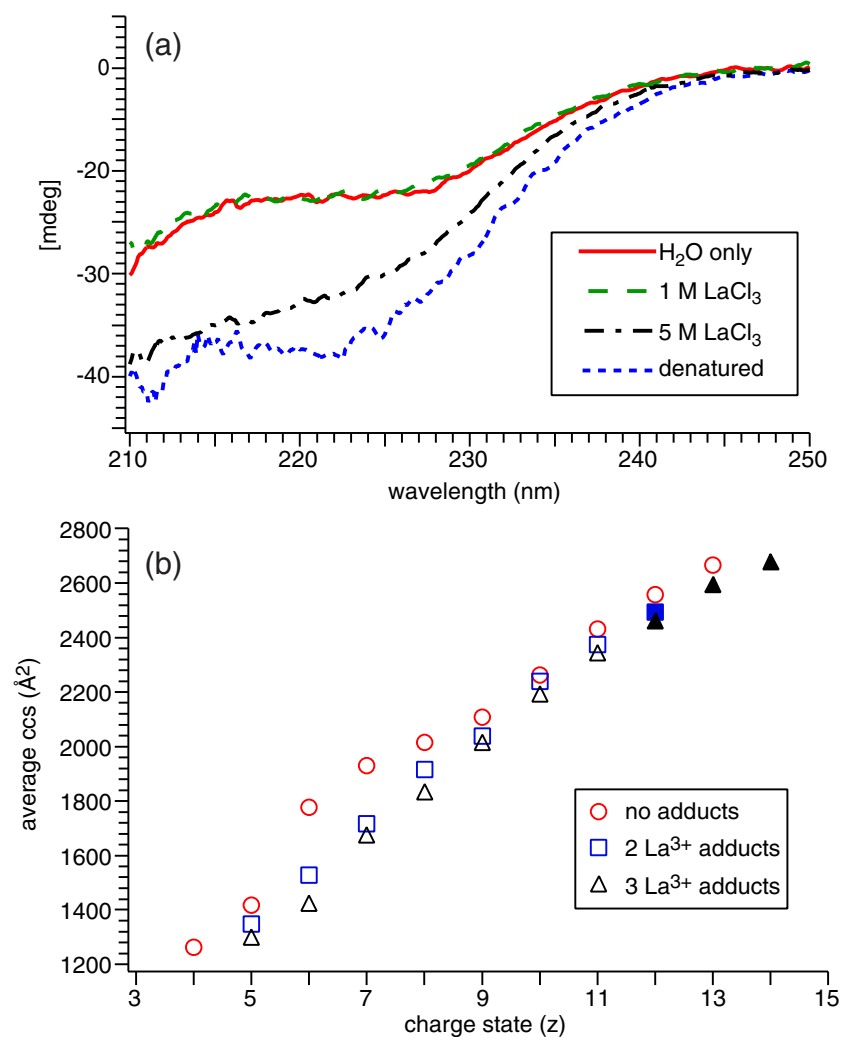

Figure 2. (a) Circular dichroism spectra between 210 to $250 \mathrm{~nm}$ for $20 \mu \mathrm{M}$ ubiquitin in $5 \mathrm{mM}$ ammonium acetate, $1 \mathrm{M}$ $\mathrm{LaCl}_{3}$ (5 mM ammonium acetate), $5 \mathrm{M} \mathrm{LaCl}_{3}$ (5 mM ammonium acetate), or 48.5/48.5/3.0 methanol/water/acetic acid ( $\mathrm{vol} / \mathrm{vol} / \mathrm{vol}$ ) (denatured). (b) Average collision cross sections as a function of ion charge state for ubiquitin with no adducts from a denatured solution (o) and from an aqueous ammonium acetate solution $(\diamond)$ without $\mathrm{LaCl}_{3}$, and with two ( $\square$ ) or three $(\Delta) \mathrm{La}^{3+}$ adducts from an aqueous ammonium acetate solution containing $1.0 \mathrm{mM} \mathrm{LaCl}$. Filled symbols are ubiquitin ions formed from an aqueous ammonium acetate solution containing $\mathrm{LaCl}_{3}$ and $m$-NBA

indicate that $1.0 \mathrm{mM} \mathrm{LaCl} 3$ does not denature ubiquitin in the initial solution, but the ion mobility experiments show that $\mathrm{La}^{3+}$-bound high charge state ions $(8+$ to $14+)$ formed from this solution have more elongated conformations than the $5+$ and $6+$ charge states formed without $\mathrm{LaCl}_{3}$. This indicates that the presence of $\mathrm{La}^{3+}$ causes ubiquitin to unfold during the late stages of the electrospray process or in the gas phase.

\section{Effects of Trivalent Metal Ion Supercharging on $E C D$}

High charge state ions typically dissociate more readily, which can increase the structural information obtained in tandem MS experiments [30, 38-41]. To determine how ECD sequence coverage is affected by supercharging with either $\mathrm{La}^{3+}$ adduction, $m$-NBA, or a combination of both,

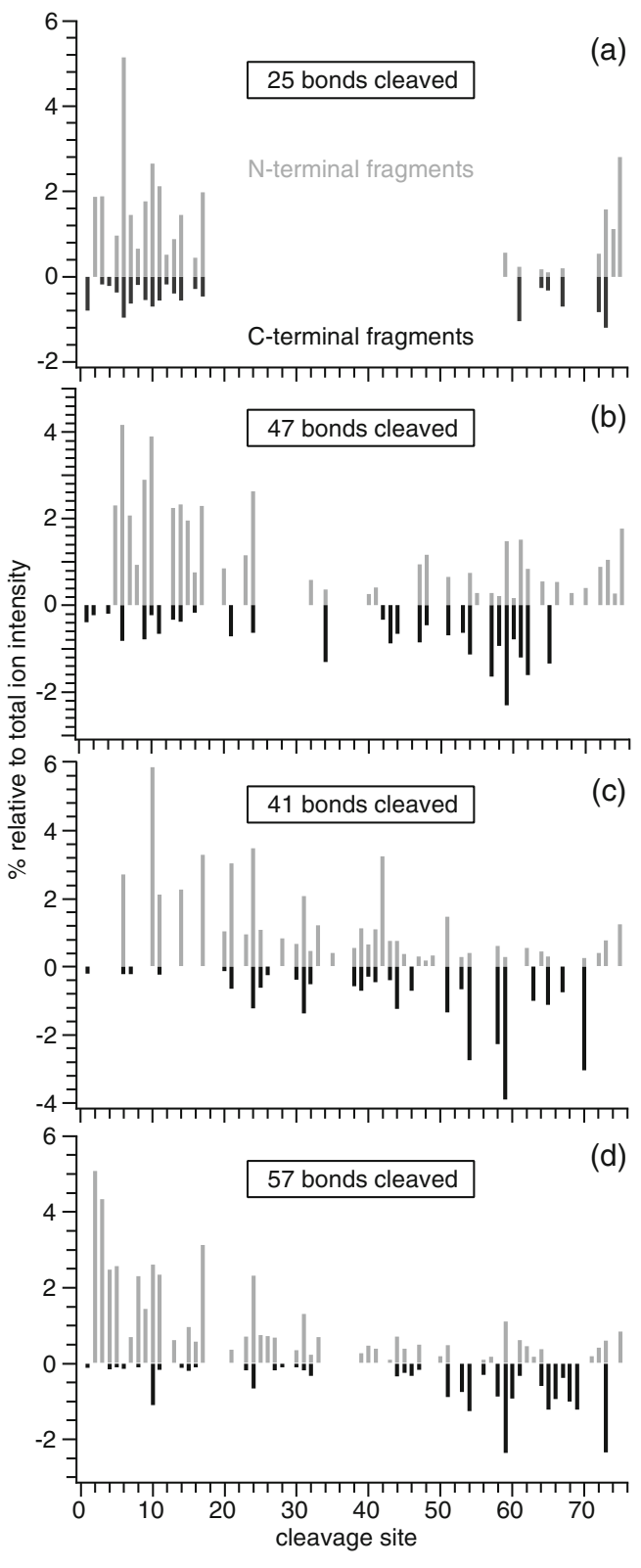

Figure 3. Relative ECD fragment ion abundances at each cleavage site for (a) (ubiquitin $+6 \mathrm{H})^{6+}$, (b) (ubiquitin+3La) ${ }^{9+}$, (c)

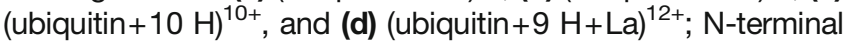
and $\mathrm{C}$-terminal fragments are represented as positive (grey) and negative (black) values, respectively

ECD spectra of the highest charge state of ubiquitin that could be isolated with sufficient $\mathrm{S} / \mathrm{N}(>\sim 1000)$ to observe most fragments were obtained from an ammonium acetate solution $(6+)$ and ammonium acetate solutions containing $\mathrm{LaCl}_{3}(9+)$, $m$-NBA $(10+)$, or both supercharging additives $(12+)$. ECD sequence coverage depends on a number of different factors, including the ion-electron interaction time, electron current, and the number of scan averages. Here, ECD conditions were optimized for (ubiquitin $+6 \mathrm{H})^{6+}$, and these same conditions were used for all other ions to directly compare the $\mathrm{Eff}_{\mathrm{EC}}$, $\mathrm{Eff}_{\text {frag, }}$, and sequence coverage between different ion charge states. ECD of (ubiquitin $+6 \mathrm{H})^{6+}$ formed from a $5 \mathrm{mM}$ 
ammonium acetate aqueous solution results primarily in the formation of the 5+ and 4+ reduced precursors. Fragmentation occurs close to the $\mathrm{N}$ - and C-termini (Figure 3a) with no fragmentation between residues 23 and 59, suggesting that residues within this region are involved in extensive noncovalent interactions $[40,41]$. ECD of (ubiquitin $+3 \mathrm{La})^{9+}$ results in additional fragmentation in the middle of the protein (Figure 3b). The electron capture and fragmentation efficiencies for (ubiquitin $+3 \mathrm{La})^{9+}$ are $9 \%$ and $21 \%$, respectively, higher than the values obtained for the fully protonated $6+$ ion (Table 2). The sequence coverage obtained from the ECD spectrum of (ubiquitin $+6 \mathrm{H})^{6+}$ is $33 \%$, whereas that for $(\text { ubiquitin }+3 \mathrm{La})^{9+}$ is $63 \%$. These results indicate the significant advantage in using $\mathrm{LaCl}_{3}$ to increase the charge state of protein ions to obtain enhanced sequence coverage and electron capture efficiency for ECD of protein ions formed from native solutions.

Extensive fragmentation occurs throughout the protein from ECD of (ubiquitin $+10 \mathrm{H})^{10+}$ formed from an aqueous solution containing $1.0 \% \mathrm{~m}$-NBA (Figure $3 \mathrm{c}$ ), and $55 \%$ sequence coverage is obtained. (ubiquitin $+3 \mathrm{La}$ ) ${ }^{9+}$ has both an $\sim 11 \%$ smaller average ccs and a lower charge state than (ubiquitin $+10 \mathrm{H})^{10+}$, yet greater sequence coverage is obtained for the $\mathrm{La}^{3+}$ adducted ion. ECD of (ubiquitin+ $9 \mathrm{H}+\mathrm{La})^{12+}$ formed from a solution with both $1.0 \% \mathrm{~m}$ NBA and $1.0 \mathrm{mM} \mathrm{LaCl}_{3}$ results in even more extensive fragmentation along the backbone of the protein (Figure 3d), from which $76 \%$ sequence coverage is obtained. Thus, a 2.3fold increase in sequence coverage is obtained from the high charge state ion that is formed with both supercharging reagents compared with the ion formed from native solutions that do not contain these reagents. ECD data of (ubiquitin+ $6 \mathrm{H})^{6+}$, (ubiquitin $\left.+3 \mathrm{La}\right)^{9+}$, (ubiquitin $\left.+10 \mathrm{H}\right)^{10+}$, and (ubiquitin $+9 \mathrm{H}+\mathrm{La})^{12+}$ combined results in $89 \%$ sequence coverage for these ions that are formed from native solutions.

Similar improvements in sequence coverage occurred from ECD of high charge state ions of cytochrome $c$ formed from ammonium acetate solutions containing either $m$-NBA, $\mathrm{LaCl}_{3}$ or both compared with data obtained without supercharging additives. The $7+$ and $6+$ reduced precursors are predominantly produced by ECD of (cytochrome $c+8 \mathrm{H})^{8+}$ formed from an ammonium acetate solution, and $30 \%$ sequence coverage is obtained (Figure $4 \mathrm{a}$ ). ECD of (cytochrome $c+7 \mathrm{H}+\mathrm{La})^{10+}$ formed from an aqueous solution containing $1.0 \mathrm{mM} \mathrm{LaCl}_{3}$ results in more extensive fragmentation throughout the protein (Figure 4b); $53 \%$ sequence coverage is obtained, whereas only $43 \%$ sequence coverage is obtained from ECD of (cytochrome $c+12 \mathrm{H})^{12+}$ generated from an aqueous solution containing $1.0 \% \mathrm{~m}$-NBA (Figure $4 \mathrm{c}$ ). Using both $\mathrm{m}$-NBA and $\mathrm{LaCl}_{3}, \mathrm{ECD}$ of (cytochrome $\left.c+11 \mathrm{H}+\mathrm{La}\right)^{14+}$ results in $56 \%$ sequence coverage (Figure 4d). The sequence coverage from the combined ECD data for all four of these protein ions formed from native solutions is $76 \%$, more than double the sequence coverage obtained without these reagents.

\section{Effect of Cross Section and Trivalent Metal Ion on $E C D$}

Results presented here and from earlier studies [30, 38-41] show that greater sequence coverage is often obtained from dissociation of high charge state protein ions, which tend to have elongated conformations compared to low charge state protein ions with compact structures; (ubiquitin+ $2 \mathrm{La})^{6+}$ has an $\sim 14 \%$ smaller average ccs than that of (ubiquitin $+6 \mathrm{H})^{6+}$, and the EC efficiency, fragmentation efficiency, and sequence coverage are $7 \%, 19 \%$, and $8 \%$ lower, respectively, for (ubiquitin $+2 \mathrm{La})^{6+}$ compared with $(\text { ubiquitin }+6 \mathrm{H})^{6+}$ (Table 2). However, greater sequence coverage was not always obtained from ECD of a protein ion with a higher charge state and larger ccs. For example, $\mathrm{ECD}$ of (ubiquitin $+3 \mathrm{La})^{9+}$ results in $8 \%$ higher sequence coverage than (ubiquitin $+10 \mathrm{H})^{10+}$, even though the $9+$ ion has one less charge and $\sim 11 \%$ smaller average ccs. Similarly, (cytochrome $c+\mathrm{La}+3 \mathrm{H})^{10+}$ has a $\sim 9 \%$ smaller average ccs than (cytochrome $c+12 \mathrm{H})^{12+}$, yet ECD of the smaller, less highly charged $\mathrm{La}^{3+}$ bound ion results in $10 \%$ higher sequence coverage. These results indicate that the ccs and charge state of an ion are not the only factors

Table 2. Average Collision Cross Section $\left(\AA^{2}\right)$, \% Sequence Coverage, Electron Capture Efficiency, and Fragmentation Efficiency for Ions of Ubiquitin, Cytochrome $c$, and Lysozyme

\begin{tabular}{|c|c|c|c|c|c|}
\hline Protein & Precursor & Avg. $\operatorname{ccs}\left(\AA^{2}\right)$ & $\begin{array}{l}\text { \% Sequence } \\
\text { coverage }\end{array}$ & $\% \mathrm{Eff}_{\mathrm{EC}}$ & $\% \mathrm{Eff}_{\text {frag }}$ \\
\hline \multirow[t]{6}{*}{ Ubiquitin } & $(\mathrm{ubq}+6 \mathrm{H})^{6+}$ & 1776 & $33 \%$ & $84.3 \% \pm 0.3 \%$ & $64.7 \% \pm 1.1 \%$ \\
\hline & $(\mathrm{ubq}+2 \mathrm{La})^{6+}$ & 1527 & $25 \%$ & $77.2 \% \pm 0.7 \%$ & $45.9 \% \pm 0.8 \%$ \\
\hline & $(\mathrm{ubq}+9 \mathrm{H})^{9+}$ & 2108 & $59 \%$ & $91.9 \% \pm 0.6 \%$ & $89.5 \% \pm 0.6 \%$ \\
\hline & $(\mathrm{ubq}+3 \mathrm{La})^{9+}$ & 2014 & $63 \%$ & $93.2 \% \pm 0.9 \%$ & $85.8 \% \pm 1.7 \%$ \\
\hline & $(\mathrm{ubq}+10 \mathrm{H})^{10+}$ & 2263 & $55 \%$ & $92.4 \%$ & $89.8 \%$ \\
\hline & $(\mathrm{ubq}+9 \mathrm{H}+\mathrm{La})^{12+}$ & 2526 & $76 \%$ & $93.9 \%$ & $87.5 \%$ \\
\hline \multirow{4}{*}{ Cytochrome c } & $(\mathrm{cyt} \mathrm{c}+8 \mathrm{H})^{8+}$ & 2472 & $30 \%$ & $87.4 \%$ & $56.9 \%$ \\
\hline & $(\text { cyt c }+\mathrm{La}+7 \mathrm{H})^{10+}$ & 2718 & $53 \%$ & $88.4 \%$ & $66.9 \%$ \\
\hline & $(\text { cyt } c+12 \mathrm{H})^{12+}$ & 3000 & $43 \%$ & $89.8 \%$ & $71.8 \%$ \\
\hline & $(\text { cyt c }+\mathrm{La}+11 \mathrm{H})^{14+}$ & 3194 & $56 \%$ & $94.5 \%$ & $87.7 \%$ \\
\hline \multirow{2}{*}{ Lysozyme } & $(\text { lys }+10 \mathrm{H})^{14+}$ & 2692 & - & $72.7 \% \pm 0.6 \%$ & - \\
\hline & $(\text { lys }+\mathrm{La}+7 \mathrm{H})^{10+}$ & 2692 & - & $74.8 \% \pm 0.8 \%$ & - \\
\hline
\end{tabular}


T. G. Flick and E. R. Williams: Supercharging with Trivalent Metal lons

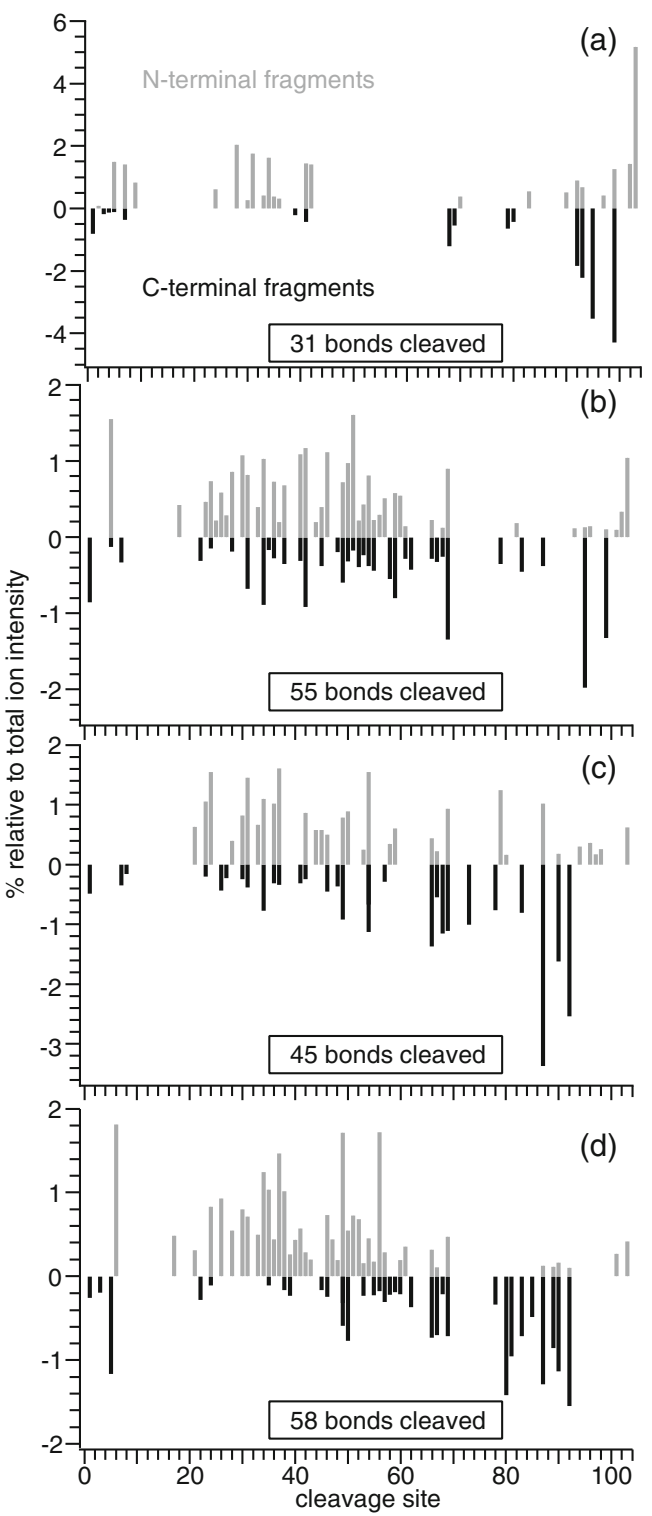

Figure 4. Relative ECD fragment ion abundances at each cleavage site for (a) (cytochrome $c+8 \mathrm{H})^{8+}$, (b) (cytochrome $c+$ $7 \mathrm{H}+\mathrm{La})^{10+}$, (c) (cytochrome $\left.c+12 \mathrm{H}\right)^{12+}$, and (d) (cytochrome $c+$ $11 \mathrm{H}+\mathrm{La})^{14+}$; N-terminal and C-terminal fragments are represented as positive (grey) and negative (black) values, respectively

in determining the extent of sequence coverage, and other characteristics such as ion shape [55] must play a significant role.

\section{Trivalent Metal Ion Supercharging with Denaturing Solution}

To determine the extent to which $\mathrm{La}^{3+}$ adducts to denatured proteins in solution, an ESI mass spectrum of ubiquitin from a denaturing solution (48.5/48.5/3 methanol/water/acetic acid) containing $1.0 \mathrm{mM} \mathrm{LaCl} 3$ was obtained (Figure $5 \mathrm{~b}$ ).

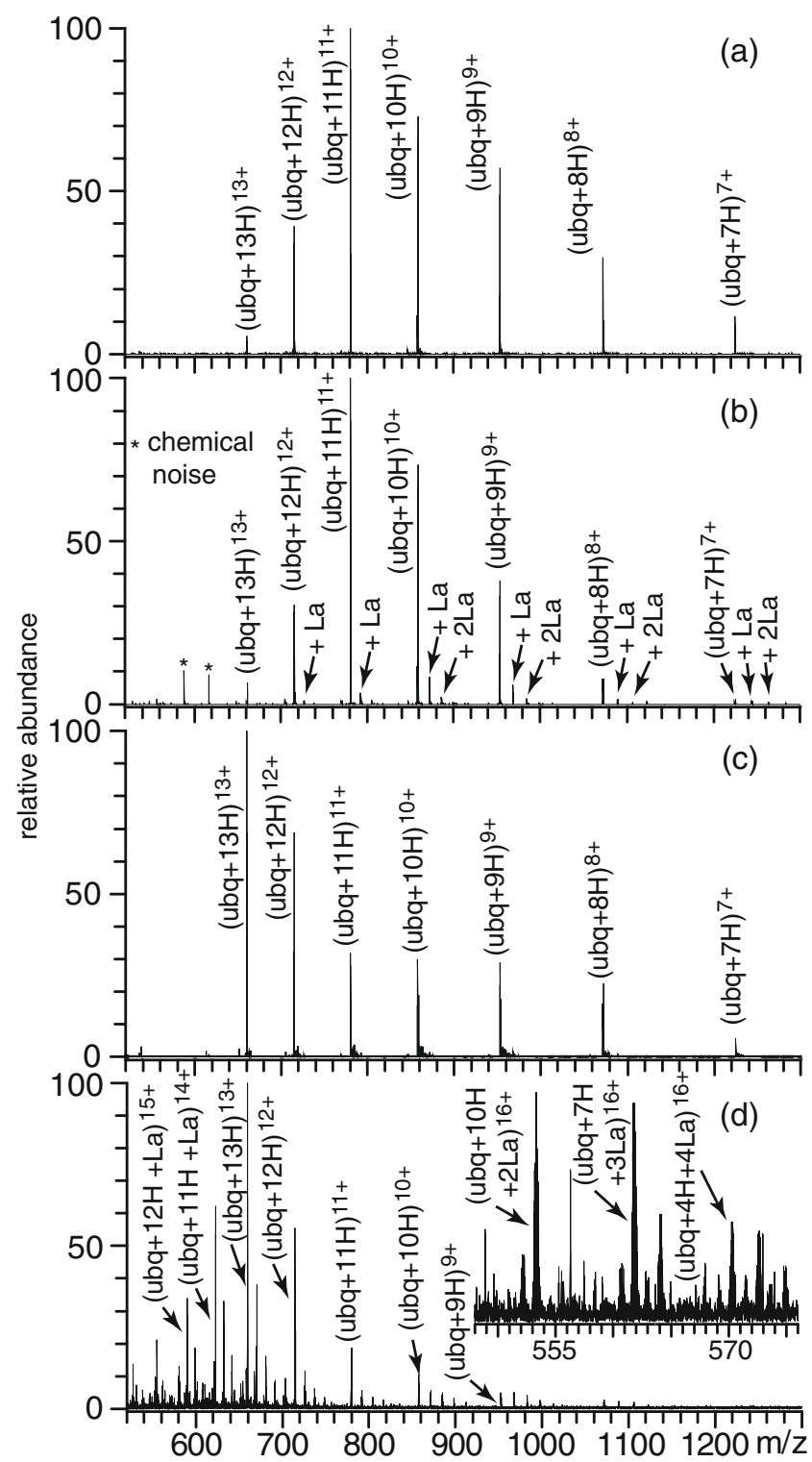

Figure 5. ESI mass spectra of $10 \mu \mathrm{M}$ ubiquitin in 48.5/48.5/ 3.0 methanol/water/acetic acid ( $\mathrm{vol} / \mathrm{vol} / \mathrm{vol}$ ) containing (a) no additives, (b) $1.0 \mathrm{mM} \mathrm{LaCl}_{3}$, (c) $1.0 \% \mathrm{~m}$-NBA, or (d) $1.0 \mathrm{mM}$ $\mathrm{LaCl}_{3}$ and $1.0 \% \mathrm{~m}$-NBA

Both the average (10.3) and maximum (13) charge states are essentially the same for the solutions with and without $\mathrm{LaCl}_{3}$ (Figure 5a). More $\mathrm{La}^{3+}$ adduction to lower charge state ions occurs, which is in striking contrast to results for aqueous solutions where $\mathrm{La}^{3+}$ adduction increases with increasing charge state. The percentage of the $7+$ and $12+$ charge states that have $\mathrm{La}^{3+}$ adducted are $79 \%$ and $32 \%$, respectively. Similar results were obtained from the denaturing solution containing $\mathrm{LaCl}_{3}$ when the metal salt was added to the protein-containing solution either before or after the denaturing reagents (methanol and acetic acid), indicating that the metal ions do not kinetically trap the protein into less stable structures in these experiments. With $1.0 \% \mathrm{~m}$-NBA, 
the average charge state increases from 10.1 to 11.8 (Figure 5c) and the maximum charge state formed is $14+$. With both $1.0 \% \mathrm{~m}$-NBA and $1.0 \mathrm{mM} \mathrm{LaCl}_{3}$, the $16+$ charge state is formed, which is three more charges than the total number of basic sites in this protein. The charge state distribution is centered about the $13+$ and the average charge state is 13.4. These results demonstrate that trivalent metal ion supercharging in denaturing solutions using ESI can be used to produce higher charge states of proteins than have previously been observed.

An ECD mass spectrum of (ubiquitin $+11 \mathrm{H}+\mathrm{La})^{14+}$ formed from a denaturing solution containing $1.0 \% \mathrm{~m}$-NBA and $1.0 \mathrm{mM} \mathrm{LaCl}_{3}$ was acquired and the resulting fragments are shown in Figure $6 \mathrm{~b}$. The low $\mathrm{S} / \mathrm{N}$ of (ubiquitin $+14 \mathrm{H})^{14+}(\sim 20)$ formed from the denaturing solution with $1.0 \% \mathrm{~m}$-NBA precludes a direct comparison to ECD of the fully protonated 14+ charge state, but fragments formed by ECD of (ubiquitin+ $13 \mathrm{H})^{13+}$ are shown in Figure 6a. The electron capture and fragmentation efficiencies of (ubiquitin $+11 \mathrm{H}+\mathrm{La}$ ) ${ }^{14+}$ are only slightly greater, $5 \%$ and $4 \%$, respectively, than for (ubiquitin+ $13 \mathrm{H})^{13+}$. The sequence coverage obtained under these conditions for both ions was $68 \%$. However, many of the ECD fragments formed from both ions are unique, resulting in $85 \%$

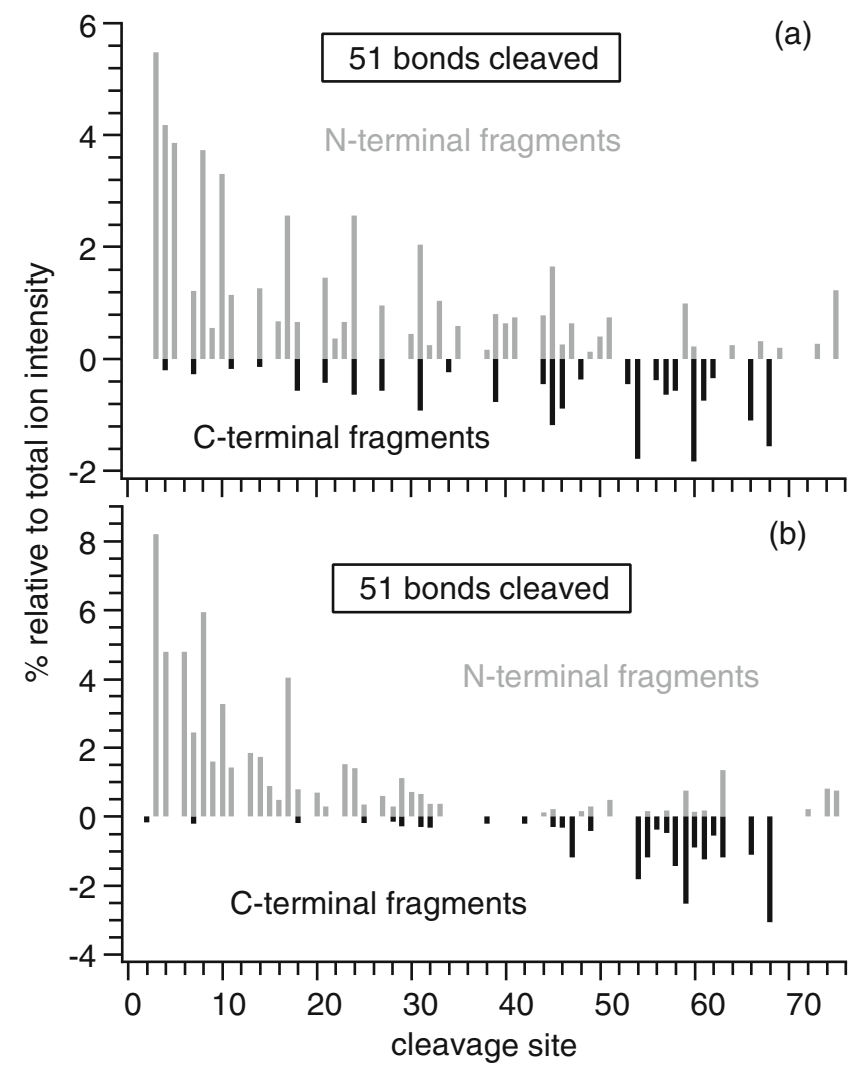

Figure 6. Relative ECD fragment ion abundances at each cleavage site for (a) (ubiquitin $+13 \mathrm{H})^{13+}$ and (b) (ubiquitin + $11 \mathrm{H}+\mathrm{La})^{14+}$; N-terminal and C-terminal fragments are represented as positive (grey) and negative (black) values, respectively sequence coverage when the data from both ions are combined. These data indicate that ECD of high charge states formed from denaturing solutions containing both $m$-NBA and $\mathrm{LaCl}_{3}$ can significantly improve the sequence coverage.

\section{Mechanism of Charging via $\mathrm{La}^{3+}$ Adduction}

The CD results show that the secondary structure content of ubiquitin is not affected in solutions with up to $1.0 \mathrm{M} \mathrm{LaCl}_{3}$, but denaturation occurs with $5.0 \mathrm{M} \mathrm{LaCl}_{3}$. For denaturation to occur in the ESI droplet, the $\mathrm{LaCl}_{3}$ concentration must increase by more than a 1000-fold from the initial $1.0 \mathrm{mM}$ concentration. By comparison, a $\sim \times 5$ enrichment of the supercharging reagent dimethyl sulfoxide occurs in the ESI droplet to produce supercharging [31]. Minimal $\mathrm{La}^{3+}$ adduction occurs for protein ions formed from denaturing solutions, and more $\mathrm{La}^{3+}$ adducts to lower charge state ions. In striking contrast, significant $\mathrm{La}^{3+}$ adduction to protein ions generated from native solutions occurs, and more $\mathrm{La}^{3+}$ adducts to higher charge state ions. These results suggest that $\mathrm{La}^{3+}$ preferentially adducts to native or native-like protein conformers during ESI. The higher charge state $\mathrm{La}^{3+}$ bound ubiquitin ions $(8+$ to $14+)$ have more elongated conformations than low charge state ions $(5+$ and $6+)$ formed from native solutions without $\mathrm{LaCl}_{3}$. These results suggest that substantial adduction of $\mathrm{La}^{3+}$ onto compact conformers of ubiquitin during ESI results in protein ions with higher charge, which subsequently adopt more unfolded gas-phase conformations, presumably due to higher Coulombic repulsion.

\section{Conclusions}

$\mathrm{LaCl}_{3}$ can significantly increase the average and maximum charge states of protein ions formed by ESI from native solutions. Charge states greater than the number of basic sites in the protein can be produced from either aqueous solutions in which the protein has a native folded structure, or denaturing solutions that contain both $\mathrm{La}^{3+}$ and $m$-NBA, even for a protein that is conformationally constrained due to native disulfide bonds. This method may be useful for increasing charging in LC/MS experiments where $\mathrm{LaCl}_{3}$ could either be added to the mobile phase or it could be added post-column as has been reported for other supercharging reagents [56].

Better ECD sequence coverage can be obtained from the high charge state protein ions formed as a result of $\mathrm{La}^{3+}$ adduction, making the information content of ECD of protein ions formed from native solutions comparable to that obtained from denaturing solutions. Addition of $1.0 \mathrm{mM}$ $\mathrm{LaCl}_{3}$ to aqueous solutions does not adversely affect the total protein ion abundance generated by ESI, but can lower the $\mathrm{S} / \mathrm{N}$ of the most abundant ion owing to the distribution of signal into ions with various numbers of $\mathrm{La}^{3+}$ adducts. However, the improved fragmentation efficiency and sequence coverage obtained for the high charge state $\mathrm{La}^{3+}$ 
adducted ions more than compensates for the reduced precursor abundance. These results indicate that trivalent metal ion supercharging can substantially increase the fragmentation of protein ions formed from native solutions, and should reduce the need to denature proteins prior to tandem MS analysis.

\section{Acknowledgments}

The authors thank the National Institutes of Health (grant no: R01GM096097) for generous financial support, and Dr. Samuel I. Merenbloom, Dr. James S. Prell, and Dr. Jeremy T. O'Brien for helpful discussion. The authors also thank Dr. Haichuan Liu and Professor Ewa Witkowska of the UCSF Sandler-Moore Mass Spectrometry Core Facility for the use of their Synapt G2 instrument.

\section{References}

1. van den Heuvel, R.H., Heck, A.J.R.: Native protein mass spectrometry: From intact oligomers to functional machineries. Curr. Opin. Chem. Biol. 8, 519-526 (2004)

2. Heck, A.J.R.: Native mass spectrometry: A bridge between interactomics and structural biology. Nat. Methods 5, 927-933 (2008)

3. Kaddis, C.S., Loo, J.A.: Native protein MS and ion mobility: Large flying proteins with MS. Anal. Chem. 79, 1778-1784 (2007)

4. Barrera, N.P., Robinson, C.V.: Advances in the mass spectrometry of membrane proteins: From individual proteins to intact complexes. Annu. Rev. Biochem. 80, 247-271 (2011)

5. Loo, J.A., Quinn, J.P., Ryu, S.I., Henry, K.D., Senko, M.W., McLafferty, F.W.: High-resolution tandem mass-spectrometry of large biomolecules. Proc. Natl. Acad. Sci. U. S. A. 89, 286-289 (1992)

6. Marshall, A.G., Hendrickson, C.L.: Charge reduction lowers mass resolving power for isotopically resolved electrospray ionization fourier transform ion cyclotron resonance mass spectra. Rapid Commun. Mass Spectrom. 15, 232-235 (2001)

7. Marshall, A.G., Hendrickson, C.L.: High-resolution mass spectrometers. Annu. Rev. Anal. Chem. 1, 579-599 (2008)

8. Perry, R.H., Cooks, R.G., Noll, R.J.: Orbitrap mass spectrometry: Instrumentation, ion motion and applications. Mass Spectrom. Rev. 27, 661-699 (2008)

9. Testa, L., Brocca, S., Grandori, R.: Charge-surface correlation in electrospray ionization of folded and unfolded proteins. Anal. Chem. 83, 6459-6463 (2011)

10. Chowdhury, S.K., Katta, V., Chait, B.T.: Probing conformationalchanges in proteins by mass-spectrometry. J. Am. Chem. Soc. 112, 9012-9013 (1990)

11. Wang, G.B., Abzalimov, R.R., Kaltashov, I.A.: Direct monitoring of heat-stressed biopolymers with temperature-controlled electrospray ionization mass spectrometry. Anal. Chem. 83, 2870-2876 (2011)

12. Williams, E.R.: Proton transfer reactivity of large multiply charged ions. J. Mass Spectrom. 31, 831-842 (1996)

13. Loo, R.R.O., Smith, R.D.: Proton-transfer reactions of multiply-charged peptide and protein cations and anions. J. Mass Spectrom. 30, 339-347 (1995)

14. Iavarone, A.T., Jurchen, J.C., Williams, E.R.: Effects of solvent on the maximum charge state and charge state distribution of protein ions produced by electrospray ionization. J. Am. Soc. Mass Spectrom. 11, 976-985 (2000)

15. Thomson, B.A.: Declustering and fragmentation of protein ions from an electrospray ion source. J. Am. Soc. Mass Spectrom. 8, 1053-1058 (1997)

16. Benkestock, K., Sundqvist, G., Edlund, P.O., Roeraade, J.: Influence of droplet size, capillary-cone distance and selected instrumental parameters for the analysis of noncovalent protein-ligand complexes by nanoelectrospray ionization mass spectrometry. J. Mass Spectrom. 39, 10591067 (2004)
17. Iavarone, A.T., Jurchen, J.C., Williams, E.R.: Supercharged protein and peptide ions formed by electrospray ionization. Anal. Chem. 73, 1455$1460(2001)$

18. Iavarone, A.T., Williams, E.R.: Supercharging in electrospray ionization: Effects on signal and charge. Int. J. Mass Spectrom. 219, 63-72 (2002)

19. Iavarone, A.T., Williams, E.R.: Mechanism of charging and supercharging molecules in electrospray ionization. J. Am. Chem. Soc. 125, 2319-2327 (2003)

20. Shvartsburg, A.A., Jones, R.C.: Attachment of metal trications to peptides. J. Am. Soc. Mass Spectrom. 15, 406-408 (2004)

21. Liu, H.C., Hakansson, K.: Divalent metal ion-peptide interactions probed by electron capture dissociation of trications. J. Am. Soc. Mass Spectrom. 17, 1731-1741 (2006)

22. Chen, X.F., Fung, Y.M.E., Chan, W.Y.K., Wong, P.S., Yeung, H.S., Chan, T.W.D.: Transition metal ions: Charge carriers that mediate the electron capture dissociation pathways of peptides. J. Am. Soc. Mass Spectrom. 22, 2232-2245 (2011)

23. Mosely, J.A., Murray, B.S., Parker, D.: Electron-capture dissociation and collision-induced dissociation of lanthanide metal-ligand complexes and lanthanide metal-ligand complexes bound to phosphopeptides. Eur. J. Mass Spectrom. 15, 145-155 (2009)

24. Lomeli, S.H., Yin, S., Loo, R.R.O., Loo, J.A.: Increasing charge while preserving noncovalent protein complexes for ESI-MS. J. Am. Soc Mass Spectrom. 20, 593-596 (2009)

25. Lomeli, S.H., Peng, I.X., Yin, S., Loo, R.R.O., Loo, J.A.: New reagents for increasing ESI multiple charging of proteins and protein complexes. J. Am. Soc. Mass Spectrom. 21, 127-131 (2010)

26. Sterling, H.J., Williams, E.R.: Origin of supercharging in electrospray ionization of noncovalent complexes from aqueous solution. J. Am. Soc. Mass Spectrom. 20, 1933-1943 (2009)

27. Sterling, H.J., Kintzer, A.F., Feld, G.K., Cassou, C.A., Krantz, B.A., Williams, E.R.: Supercharging protein complexes from aqueous solution disrupts their native conformations. J. Am. Soc. Mass Spectrom. 23, 191-200 (2012)

28. Sterling, H.J., Cassou, C.A., Trnka, M.J., Burlingame, A.L., Krantz, B.A., Williams, E.R.: The role of conformational flexibility on protein supercharging in native electrospray ionization. Phys. Chem. Chem. Phys. 13, 18288-18296 (2011)

29. Sterling, H.J., Daly, M.P., Feld, G.K., Thoren, K.L., Kintzer, A.F., Krantz, B.A., Williams, E.R.: Effects of supercharging reagents on noncovalent complex structure in electrospray ionization from aqueous solutions. J. Am. Soc. Mass Spectrom. 21, 1762-1774 (2010)

30. Sterling, H.J., Williams, E.R.: Real-time hydrogen/deuterium exchange kinetics via supercharged electrospray ionization tandem mass spectrometry. Anal. Chem. 82, 9050-9057 (2010)

31. Sterling, H.J., Prell, J.S., Cassou, C.A., Williams, E.R.: Protein conformation and supercharging with DMSO from aqueous solution. J. Am. Soc. Mass Spectrom. 22, 1178-1186 (2011)

32. Grimm, R.L., Beauchamp, J.L.: Evaporation and discharge dynamics of highly charged multicomponent droplets generated by electrospray ionization. J. Phys. Chem. A 114, 1411-1419 (2010)

33. Douglass, K.A., Venter, A.R.: Investigating the role of adducts in protein supercharging with sulfolane. J. Am. Soc. Mass Spectrom. 23, 489-497 (2012)

34. Hogan, C.J., Loo, R.R.O., Loo, J.A., de la Mora, J.F.: Ion mobilitymass spectrometry of phosphorylase $\mathrm{b}$ ions generated with supercharging reagents but in charge-reducing buffer. Phys. Chem. Chem. Phys. 12, 13476-13483 (2010)

35. Sze, S.K., Ge, Y., Oh, H., McLafferty, F.W.: Top-down mass spectrometry of a 29-kDa protein for characterization of any posttranslational modification to within one residue. Proc. Natl. Acad. Sci. U. S. A. 99, 1774-1779 (2002)

36. Sheng, Y., Loo, J.A.: Top-down mass spectrometry of supercharged native protein-ligand complexes. Int. J. Mass Spectrom. 300, 118-122 (2011)

37. Valeja, S.G., Tipton, J.D., Emmett, M.R., Marshall, A.G.: New reagents for enhanced liquid chromatographic separation and charging of intact protein ions for electrospray ionization mass spectrometry. Anal. Chem. 82, 7515-7519 (2010)

38. Iavarone, A.T., Williams, E.R.: Collisionally activated dissociation of supercharged proteins formed by electrospray ionization. Anal. Chem. 75, 4525-4533 (2003)

39. Madsen, J.A., Brodbelt, J.S.: Comparison of infrared multiphoton dissociation and collision-induced dissociation of supercharged peptides in ion traps. J. Am. Soc. Mass Spectrom. 20, 349-358 (2009) 
40. Breuker, K., Oh, H.B., Horn, D.M., Cerda, B.A., McLafferty, F.W.: Detailed unfolding and folding of gaseous ubiquitin ions characterized by electron capture dissociation. J. Am. Chem. Soc. 124, 6407-6420 (2002)

41. Breuker, K., Oh, H.B., Lin, C., Carpenter, B.K., McLafferty, F.W.: Nonergodic and conformational control of the electron capture dissociation of protein cations. Proc. Natl. Acad. Sci. U. S. A. 101, 14011-14016 (2004)

42. Kharlamova, A., Prentice, B.M., Huang, T.Y., McLuckey, S.A.: Electrospray droplet exposure to gaseous acids for the manipulation of protein charge state distributions. Anal. Chem. 82, 7422-7429 (2010)

43. Sterling, H.J., Cassou, C.A., Susa, A.C., Williams, E.R.: Electrothermal supercharging of proteins in native electrospray ionization. Anal. Chem. 84, 3795-3801 (2012)

44. Jurchen, J.C., Williams, E.R.: Origin of asymmetric charge partitioning in the dissociation of gas-phase protein homodimers. J. Am. Chem. Soc. 125, 2817-2826 (2003)

45. Marshall, A.G., Wang, T.L., Ricca, T.L.: Tailored excitation for fourier transform ion cyclotron resonance mass spectrometry. J. Am. Chem. Soc. 107, 7893-7897 (1985)

46. Schnier, P.D., Jurchen, J.C., Williams, E.R.: The effective temperature of peptide ions dissociated by sustained off-resonance irradiation collisional activation in fourier transform mass spectrometry. J. Phys. Chem. B 103, 737-745 (1999)

47. Bush, M.F., Hall, Z., Giles, K., Hoyes, J., Robinson, C.V., Ruotolo, B.T.: Collision cross sections of proteins and their complexes: A calibration framework and database for gas-phase structural biology. Anal. Chem. 82, 9557-9565 (2010)
48. Ruotolo, B.T., Benesch, J.L.P., Sandercock, A.M., Hyung, S.J., Robinson, C.V.: Ion mobility-mass spectrometry analysis of large protein complexes. Nat. Protoc. 3, 1139-1152 (2008)

49. Iavarone, A.T., Udekwu, O.A., Williams, E.R.: Buffer loading for counteracting metal salt-induced signal suppression in electrospray ionization. Anal. Chem. 76, 3944-3950 (2004)

50. Pan, P., Gunawardena, H.P., Xia, Y., McLuckey, S.A.: Nanoelectrospray ionization of protein mixtures: Solution $\mathrm{pH}$ and protein $\mathrm{pI}$. Anal. Chem. 76, 1165-1174 (2004)

51. Brutscher, B., Bruschweiler, R., Ernst, R.R.: Backbone dynamics and structural characterization of the partially folded a state of ubiquitin by $\mathrm{H}-1, \mathrm{C}-13$, and $\mathrm{N}-15$ nuclear magnetic resonance spectroscopy. Biochemistry 36, 13043-13053 (1997)

52. Myung, S., Badman, E.R., Lee, Y.J., Clemmer, D.E.: Structural transitions of electrosprayed ubiquitin ions stored in an ion trap over 10ms to 30s. J. Phys. Chem. A 106, 9976-9982 (2002)

53. Hoaglund, C.S., Valentine, S.J., Sporleder, C.R., Reilly, J.P., Clemmer, D.E.: Three-dimensional ion mobility TOF-MS analysis of electrosprayed biomolecules. Anal. Chem. 70, 2236-2242 (1998)

54. Prell, J.S., Flick, T.G., Oomens, J., Berden, G., Williams, E.R.: Coordination of trivalent metal cations to peptides: Results from IRMPD spectroscopy and theory. J. Phys. Chem. 114, 854-860 (2010)

55. Robinson, E.W., Leib, R.D., Williams, E.R.: The role of conformation on electron capture dissociation of ubiquitin. J. Am. Soc. Mass Spectrom. 17, 1469-1479 (2006)

56. Miladinović, S.M., Fornelli, L., Lu, Y., Piech, K.M., Girault, H.H., Tsybin, Y.O.: In-spray supercharging of peptides and proteins in electrospray ionization mass spectrometry. Anal. Chem. 84, 4647-4651 (2012) 